\title{
PELATIHAN MINDFULNESS SINGKAT UNTUK MENINGKATKAN SELF ACCEPTANCE BAGI ANAK KHUSUSNYA REMAJA DI PANTI ASUHAN MUHAMMADIYAH 3 CABANG BANJARMASIN
}

\author{
Eka Sri Handayani, Farial, Ainun Heiriyah
}

Fakultas Keguruan dan Ilmu Pendidikan, Universitas Islam Kalimantan

E-mail : ekasrihandayani678@gmail.com)

\begin{abstract}
ABSTRAK
Panti Asuhan merupakan salah satu tempat penampungan anak -anak yatim yang mempunyai tujuan membantu meringankan beban orang tuanyaagar dapat mengenyam pendidikan. Selain itu Panti Asuhan juga memiliki tujuan agar kelak setelah keluar dari Panti Asuhan menjadi orang yang bermakna bagi diri sendiri, keluarga, maupun masyarakat. Seiring dengan majunya tekhnologi, informasi dan arus globalisasi tersebut para santri dihadapkan pada berbagai benturan yang ada disekelilingnya, baik dilingkungan sosial, ekonomi, budaya dan sebagainya. Sehingga timbul rasa kurang percaya diri, cemas, depresi, dan kesepian. Pada dasarnya setiap orang normal senantiasa menginginkan dirinya menjadi orang yang bermanfaat baik bagi diri sendiri, keluarga, maupun lingkungan masyrakatnya. Self acceptance dibutuhkan oleh setiap individu untuk mencapai keharmonisan hidup, karena pada dasarnya tidak ada manusia yang diciptakan oleh Allah SWT tanpa kekurangan. Untuk menghadapi kekurangan yang dimiliki,dibutuhkan sikap menerima apapun baik kelebihan maupun kekurangan dirinya. Tujuan dalam pelatihan ini agar mereka berlatih memiliki kesadaran penuh dalam mengerjakan berbagai hal, focus dan dapat meningkat self acceptance nya atau penerimaan diri nya baik keadaan dirinya, internal dan eksternal baik dalam studi dan bersosialisasi.
\end{abstract}

Kata Kunci : Mindfulness, Self Acceptance

\section{PENDAHULUAN}

Di Indonesia, terdapat sejumlah anak yang kurang beruntung nasibnya dibanding anak-anak lain seusianya. Sebagai contoh kondisi bahwa terdapat anak yang kurang beruntung, beberapa diantaranya yaituseperti anak jalanan, anak-anak yang ditelantarkan oleh orangtuanya, maupun anak-anak yang tidak memiliki orangtua. Berdasarkan data yang diperoleh dari KemensosRI (Kementrian Sosial Republik Indonesia) tahun 2010, jumlah anak terlantar di Indonesia masih mencapai 5,4 jutajiwa. Biasanya anak-anak yang ditelantarkan atau tidak memiliki orangtua dimasukkan ke dalam panti asuhan (Erwansyah, 2013).

Anak-anak yang kurang beruntung seperti anak-anak yatim piatu yang tinggal di panti asuhan atau anak jalanan juga dapat bertempat tinggal di panti asuhan. Jumlah panti asuhan di 
seluruh Indonesia diperkirakan antara 5.000-8.000 yang mengasuhsampai setengah juta anak. Pemerintah Indonesia hanya memiliki dan menyelenggarakan sedikit dari panti asuhan tersebut, lebih dari $99 \%$ panti asuhan diselenggarakan oleh masyarakat, terutama organisasi keagamaan (Sudrajat, 2008). Bertempat tinggal dan hidup di panti asuhan bukanlah hal yang mudah bagi anak, khususnya bagi remaja. Karena mereka tidak mendapatkan hangatnya kasih sayang orang tua kandung. Santi (2011) dalam makalahnyamenjelaskan bahwa dalam penelitian yang telah dilakukan oleh lembaga Save The Children, terdapat kasus-kasus eksploitasi terhadap anak di dalam panti asuhan, sehingga fungsi panti asuhan sebagai lembaga asuhan alternatif tidak dapat melindungi anak yang berada di luar asuhan keluarga secara aman. Sebaliknya anak-anak tumbuh dalam lingkungan yang tidak kondusif, tidak protektif yang akan mengganggu terhadap tumbuh kembang anak.

Self acceptance dibutuhkan oleh setiap individu untuk mencapai keharmonisan hidup, karena pada dasarnya tidak ada manusia yang diciptakan oleh Allah SWT tanpa kekurangan. Untuk menghadapi kekurangan yang dimiliki,dibutuhkan sikap menerima apapun baik kelebihan maupun kekurangan dirinya. Self acceptance yang baik ialah kemampuan seseorang untuk hidup dan bergaul secara wajar terhadap lingkungannya, sehingga remaja merasa puas terhadap diri sendiri dan lingkungan (Willis, 2005). Self acceptance yang baik akan menjadi salah satu bekal penting karena akan membantu remaja pada saat terjun ke dalam masyarakat luas. Meskipun demikian, tampaknya self acceptance yang baik bukanlah hal yang mudah (Hurlock, 1978).

Pengertian dari penerimaan sendiri merupakan perilaku positif individu dapat menangani situasi dirinya saat emosional yang meliputi rasa marah, cemas, takut tanpa merusak ketentraman dan keamanan masyarakat lain. Seseorang dikatakan mempunyai penerimaan diri yang baik jika mampu memahami dirinya sesuai dengan keadaan yang sedang dihadapi, bukan sesuai dengan apa yang diharapkan. (Eka Sh,dkk 2020).

\section{METODE PELAKSANAAN}

\begin{tabular}{ccr} 
Bentuk & \multicolumn{2}{c}{ kegiatan yang } \\
diselenggarakan & yaitu & serangkaian
\end{tabular}


kegiatan yang dilaksanakan dalam bentuk materi, diskusi dan treatment yang meliputi:

Penyampaian materi mengenai:

a. Memberikan materi tentang self acceptance dan apa Pelatihan Mindfulness

b. Memberikan training atau pelatihan untuk meningkatkan self acceptance

c. Pendampingan dalam memberikan materi dan training untuk meningkatkan self acceptance

d. Training dan Role Play : Training atau pelatihan untuk meningkatkan self acceptance dan warga binaan di minta untuk melakukan Role play dengan permasalahan mereka masing-masing.

Langkah-langkah

dalam

Mindfulness

PRESENT

MOMENT

(MINDFULNESS, BODY, MIND

AND SOUL ) :

\section{EXERCISE}

1). FOCUS EXERCISE :

2). Bagaimana rasanya makananmu ?

3). Analisa ?

4). Rasakan ?

5). Jabarkan ? Setiap detilnya ?

6). Pilih 1 Objek apa saja yang ada di sekitar kalian?

7). Apa yang ada di ruangan ? Amati ?

8). Apa Saja yang skr menempel di tubuh ? Amati ?

9). Atau saat ini sedang makan / Ketika saat makan terlihat seperti apa makanan itu ?

10). Poinntnya adalah memberikan AWARE atau Pikiran Sadar dan keep Focus.... Melatih otak agar tidak terbawa pikiran-pikiran dari masa lalu atau ,mengkhawatrkan masa depan...

11). lainnya dan berusaha menutarakan maksud dan tujuan sampai dengan apa yang dirasakan.

1. SCAN YOU BODY? Pernah gak dialog sama tubuh ?

- Dialog sama tubuh, Say THANK YOU.. Sama Kulit... Jantung... Nafas... Tangan... Kaki dll ....

\section{Mindfulness Immersed} (Perenungan Penuh Perhatian) .... : Misal : Berdoa, Meditasi..... Tidak Multitasking c/o : Ketika nonton bioskop ?? FOCUS sampai film selesai..... ? $\mathrm{Cb}$ rasakan ketika nonton tetapi 
tidak mempehatikan apa yan di dapatkan?

3. Gratitude Journal : (Jurnal Bersyukur / Jurnal Berterima kasih ) : tuliskan 5 hal yang sdh ada syukuri hari ini ? tiap pagi ulangi dengan 5 hal yang berbeda

4. GET OUT IN NATURE Keluar Ke Alam )

- Pernahkan kalian mengamati pohon?

- Pernahkan mengamati bintang ?

- Pernahkah mengamati awan?

- Pernahkan mengamati air? Batu dll ?

\section{5 Sense Technique}

Penglihatan, Penciuman, Perasa, Peraba, Pendengaran ) : Memasak, Merawat Tanaman.... dll

Ex : Minum Kopi

Melihat bagaimana kopi di seduh dan bagaimana air $d$ seduh ke kopi, dengarkan suara air panas ketika d tuang, rasakan bau kopi yang menyegarkan, rasakan bagaimana rasa kopinya dan jabarkan... ( melatih focus dan aware terhadap setiap momen kegiatan sehingga bukan menghadirkan pikiran cemas, pikiran masalah-masalah pada saat membuat kopi tsb ).

\section{Mindful}

Breathing

\section{Technique :}

- yoga meditation

- Focus On Breathe 556 ( 5 hitungan tari napas, 5 hitungan tahan napas, 6 hitungan buang napas “ say it LOUDNESSSS "huuuhhhhh.... ) d ulang beberapa kali.. Dalam 1 minggu

7. Daily Inttention ( Niat Harian... Niat Positif ) : tanamkan nniat-iat positif dalam rutinitas harian

8. Currently Exercise : Semua 1-9 d ulang-ulang hingga menjadi Habit dan perilaku positif... Sehingga merasakana benar mind, body and soul hadir bersamaan.

9. Re Arrange Space (Atur lagi ruang ) : utk dir sendiri, atur jadwal, me time... Kerja ... Sosiaal... Anak..... Keluarga dll.... EX : sebelum tdr matikan hape 30 menit sblm 
$\begin{array}{lll}\text { tdr....beri } & \text { ruang } & \text { otak } \\ \text { menyimpan } & \text { memori } & \text { yang }\end{array}$

baik2 d alalam bawah sadar.

Begitu pula saat bangun

pagi... Jangan lupa bersyukur

dan memulailah dengan niat-

Sebelum melaksanakan

kegiatan Pengabdian Kepada

Masyarakat ini maka diperlukan persiapan-persiapan..

Adapun

persiapan yang dilakukan antara lain:

\section{Persiapan Kegiatan}

1. Melakukan observasi di lokasi mitra yang akan diberikan Pelatihan Mindfulness singkat

2. Menentukan tema yang akan disampaikan dan berdiskusi dengan pihak panti asuhan mengenai kegiatan yang akan dilakukan serta mengurus surat ijin yang diperlukan untuk kegiatan pelaksanaan. Pertemuan ini dilakukan pada bulan Januari 2021.

3. Menentukan waktu pelaksanan Pelatihan Mindfulness Singkat dan lamanya kegiatan yang akan dilakukan,

4. Mempersiapkan materi guna menunjang kegiatan Pelatihan Mindfulness singkat. Persiapan ini dilakukan secara matang agar noat positif yang akan d

lakukan hari ini / tiap harinya.

\section{HASIL KEGIATAN DAN \\ PEMBAHASAN}

pada saat pelaksanaan dapat berjalan dengan lancar, sehingga meminimalisir kendala yang akan terjadi.

\section{Pelaksanaan Kegiatan}

Kegiatan pengabdian kepada masyarakat ini dilaksanakan pada tanggal 18 februari 2021. Kegiatan di mulai pada pukul 08.00 sampai dengan pukul 11.30 WITA, bertempat di panti asuhan putra Muhammadiyah 3 Banjarmasin. Kegiatan terapi ini diadakan dikarekanan sebagian bagi remaja bertempat tinggal dan hidup di panti asuhan bukanlah hal yang mudah bagi anak ataupun remaja, khususnya bagi remaja karena mereka tidak mendapatkan hangatnya kasih sayang dari anggota keluarga lainnya seperti orangtua kandung, ataupun saudara kandung. Apalagi dengan tinggal di panti asuhan, remaja tersebut sudah pasti tidak mempunyai fasilitas pribadi seperti remaja lainnya yang masih mempunyai orangtua kandung dan tinggal bersama orangtua. Oleh karena itu pelatihan 
Mindfulness Singkat ini bertujuan untuk membantu anak-anak lebih menerima dengan keadaan dirinya dan lebih ke arah self acceptance sehingga mampu berkembang dan beradaptasi dengan relasi sosialnya tanpa rasa minder

- Penyampaian Materi Self Acceptance dan Mindfulness Singkat oleh Eka Sri Handayani M.Psi, Psikolog dan Farial M. Pd (Materi Terlampir) setelah diberikan materi audience diberikan Role Playing, mereka membuat kelompok terdiri dari 3 kelompok beranggotan 4 orang. Masing-masing kelompok mengerjakan tugas secara individual, dan role playing di lakukan masing-masing kelompok di tunjuk perwakilan dan anggota kelompok lainnya memberikan penilaian. Selanjutnya praktek pada 3 kelompok diberikan materi exercise. Dimana dalam exercise tersebut mereka belajar dalam 10 tahapan dan dalam 10 tahapan itu salah satunya ada belajar tentang breathing exercise atau pelatihan pernapasan, dan mereka juga belajar cara membedakan pikiran, badan dan jiwa (Mind,
Body, Soul) berada pada saat sekarang, berlatih focus dan menuliskan kalimat-kalimat afirmasi positif dan kalimatkalimat tentang bersyukur.

- Germer, Siegel, dan Fulton (2005) menyebutkan mindfulness adalah suatu kondisi kesadaran pada saat ini dengan penuh penerimaan.

- Mindfulness menekankan pada kesadaran, menjadi sadar sepenuhnya pada hal yang terjadi saat ini dengan mengalihkan pengalaman yang lain, diterima sepenuhnya tanpa penilaian (Mace, 2008)

- Tujuan dalam pelatihan ini agar mereka berlatih memiliki kesadaran penuh dalam mengerjakan berbagai hal, focus dan dapat meningkat self acceptance nya atau penerimaan diri nya baik keadaan dirinya, internal dan eksternal baik dalam studi dan bersosialisasi.

- Target pencapaian : Peserta memiliki pengetahuan tentang konsep, aspek serta faktor yang dapat mempengaruhi kepercayaan diri ketika tampil dan berbicara di depan umum 
Peserta memiliki penilaian terhadap dirinya sendiri tentang level kepercayaan diri berbicara di depan publik mereka

Materi-Mindfulness

Materi - Mindfulness

PRESENT

MOMENT

(MINDFULNESS, BODY, MIND AND SOUL ) : EXERCISE

FOCUS EXERCISE :

Bagaimana rasanya makananmu ? Analisa ? Rasakan ? Jabarkan ? Setiap detilnya ?

- Pilih 1 Objek apa saja yang ada di sekitar kalian?

- Apa yang ada di ruangan ? Amati ?

- Apa Saja yang skr menempel di tubuh ? Amati ?

- Atau saat ini sedang makan / Ketika saat makan terlihat seperti apa makanan itu ?

- Poinntnya adalah memberikan AWARE atau Pikiran Sadar dan keep Focus.... Melatih otak agar tidak terbawa pikiran-pikiran dari masa lalu atau ,mengkhawatrkan masa depan...

- lainnya dan berusaha menutarakan maksud dan tujuan sampai dengan apa yang dirasakan.

- SCAN YOU BODY ? Pernah gak dialog sama tubuh ? Dialog sama tubuh , Say THANK YOU.. Sama Kulit... Jantung... Nafas... Tangan... Kaki dll ....

\section{- Mindfulness Immersed} (Perenungan Penuh Perhatian) ..... : Misal : Berdoa, Meditasi..... Tidak Multitasking c/o : Ketika nonton bioskop ?? FOCUS sampai film selesai...... ? $\mathrm{Cb}$ rasakan ketika nonton tetapi tidak mempehatikan apa yan di dapatkan?

- Gratitude Journal : (Jurnal Bersyukur / Jurnal Berterima kasih ) : tuliskan 5 hal yang sdh ada syukuri hari ini ? (tiap pagi ulangi dengan 5 hal yang berbeda

- GET OUT IN NATURE ( Keluar Ke Alam )

- Pernahkan kalian mengamati pohon ?

- Pernahkan mengamati bintang ?

- Pernahkah mengamati 
awan ?

- Pernahkan mengamati air ? Batu dll ?

- 5 Sense Technique ( Penglihatan, Penciuman, Perasa, Peraba,

Pendengaran) : Memasak, Merawat Tanaman.... dll

Ex : Minum Kopi

Melihat bagaimana kopi di seduh dan bagaimana air d seduh ke kopi, dengarkan suara air panas ketika $d$ tuang, rasakan bau kopi yang menyegarkan, rasakan bagaimana rasa kopinya dan jabarkan... ( melatih focus dan aware terhadap setiap momen kegiatan sehingga bukan menghadirkan pikiran cemas, pikiran masalahmasalah pada saat membuat kopi tsb ).

- Mindful

Breathing

Technique :

- yoga meditation

- Focus On Breathe 556 ( 5 hitungan tari napas, 5 hitungan tahan napas, 6 hitungan buang napas “ say it LOUDNESSSS "huuuhhhhh.... ) d ulang

beberapa kali.. Dalam 1

minggu

- Daily Inttention ( Niat Harian... Niat Positif ) : tanamkan nniat-iat positif dalam rutinitas harian

- Currently Exercise : Semua 1-9 d ulang-ulang hingga menjadi Habit dan perilaku positif... Sehingga merasakana benar mind, body and soul hadir bersamaan.

- Re Arrange Space ( Atur lagi ruang ) : utk dir sendiri, atur jadwal, me time... Kerja ... Sosiaal... Anak..... Keluarga dll.... EX : sebelum tdr matikan hape 30 menit sblm tdr....beri ruang otak menyimpan memori yang baik2 d alalam bawah sadar. Begitu pula saat bangun pagi... Jangan lupa bersyukur dan memulailah dengan niatnoat positif yang akan d lakukan 

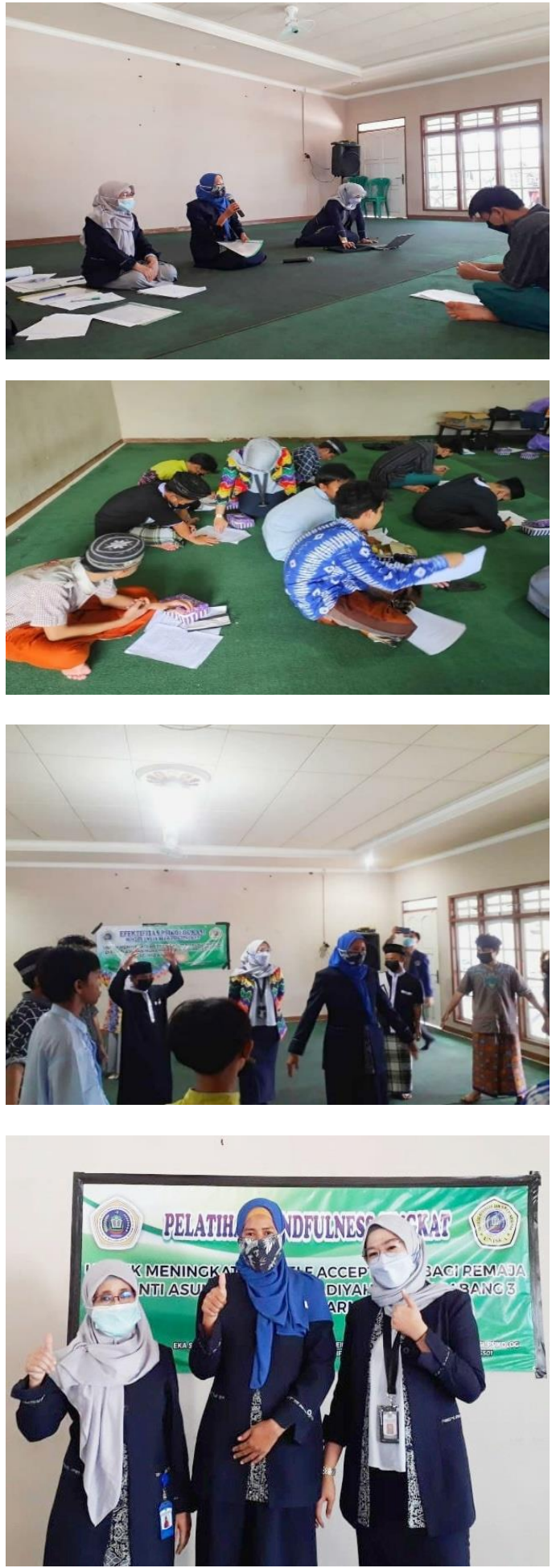

\section{KESIMPULAN}

Pelaksanaan

kegiatan

berlangsung sangat baik dan berjalan dengan sukses. Hal ini terlihat dari keantusiasan para peserta disetiap sesi kegiatan. Diharapkan setelah kegiatan ini agar peserta kegiatan mampu mengaplikasikan keterampilan Mindfulness dan self acceptance ini sehari-hari pada kegiatan. Agar mampu mengenal diri lebih baik lagi dan mampu menerima diri keadaan diri dan menyesuaikan diri sehingga mampu mengerjakan berbagai kegiatan selama menjadi Anak-anak Binaan di Panti Asuhan dan mengambil manfaat dari setiap kegiatan yang diselnggrakan baik kepada pembangunan karakter diri juga pengembangan diri pada umumnya selain itu tujuan daripada pelatihan ini adalah :

1. Tujuan dari pelatihan ini memberikan materi mindfulness dan memberikan pelatihan tentang bagaimana mengenali Self Acceptance apakah negatif ataupun psoitif dan bagaimana meningkatkanya dan mengetahui bagaimana self acceptance, pada skala Self Acceptance, Adanya permasalahan- permasalahan peneyesuaian diri, baik lingkungan sosial dan dari dalam diri sendiri dalam hal self acceptance sebagai anak yang di asuh oleh panti asuhan pada self acceptance 
2. Bagaimana dalam self acceptance yang di miliki remaja di panti asuhan Muhammadiyah 3 Banjarmasin.

Hal ini bisa di lihat dari semua peserta sebanyak 13 orang (Peserta Remaja Panti Asuhan) yang mengikuti pelatihan, sebelumnya mendapatkan yang mengikuti pelatihan, hasil pretest penerimaan diri mempunyai rata-rata 80.08, setelah dilakukan pelatihan mendapatkan hasil posttest penerimaan diri dengan rata-rata 102.69. Hal ini berarti bahwa materi yang disampaikan benar-benar menjadi sebuah refensi tambahan dalam peningkatan kemampuan baik self Self Acceptance. Mampu memberikan remaja yang khususnya berada di panti asuhan pandangan dan gambaran bagaimana seharusnya dalam menyikapi self acceptance yang negatif dan setidaknya lebih bisa mengetahui dan belajar lagi bagaimana harus menerima dengan keadaan diri dan wajib menyesuaikan selama menjadi individu yang terus akan berkembang dn berkarya. Bentuk evaluasi dari kegiatan pengabdian kepada masyarakat ini setelah dianalisis menghasilkan data peserta sebanyak 13 orang (Peserta Remaja Panti Asuhan) yang mengikuti pelatihan, sebelumnya mendapatkan yang mengikuti pelatihan, hasil pretest penerimaan diri mempunyai rata-rata 80.08 , setelah dilakukan pelatihan mendapatkan hasil posttest penerimaan diri dengan rata-rata 102.69

\section{DAFTAR PUSTAKA}

American Psychiatric Association (APA), 2016. Practice Gaudelines for the Psychiatric Evaluation of Adults. 3rd. USA: APA

Brown, K. W., Ryan, R. M., \& Creswell, J. D. (2007). Mindfulness: Theoretical foundations and evidence for its salutary effects. Psychological Inquiry, 18(4), 211-237.

Erwansyah. 21 Juli 2013. Tentang panti yatim indonesia. http://pantiyatim.or.id/

Gunarsa, S.D. 2008. Dasar dan teori perkembangan anak. Gunung Mulia, Jakarta.

Germer, C. K., Siegel, R. D., \& Fulton P. R. (Eds.). (2005). Mindfulness and psychotherapy. New York: Guilford Press.

Handayani, Eka \& Rudy Haryadi, Pelatihan Peningkatan Self Concept dan Self Acceptance Pada Warga Binaan di LP Perempuan Kelas II A Martapura, Jurnal Pengabdian Al-Ikhlas 6(2) 2020.

Hurlock, E. (1978). Personality Development.Tokyo: McGrawHill Publishing Company.

Hurlock, E. B. (1986). Personality Development.New Delhi: McGraw-Hill Inc 
Germer, C. K., Siegel, R. D., \& Fulton, P. R. (2005). Mindfulness and psychotherapy. New York: The Guilford Press.

Gussak, D. 2007. Comparing The Effectiviness of Art Therapy on Depression and Locus of Control on Male and Famale Inmaters. The Arts in Psychotherapy.

Gussak, D. 2009. The Effects Art Theraphy on Male and Famale inmtes : Advancing the Reserchbase. The Arts in Psychotheraphy.

Karen Glanz, Barbara K. Rimer, K. Viswanath, 2008. Health Behavior And Health Education Theory, Research, and Practice. 4th.EDITION.

St.

Fransisco:Jossey-Bass

Kabat-Zinn, J. (1990). Full catastrophe living: Using the wisdom of your body and mind to face stress, pain, and illness. New York: Bantam Dell.

Mace, C. (2008). Mindfulness and mental health: Therapy, theory, and science. New York: Routledge.

Meilina Clara Priscilla, 2013. Skripsi: Dampak Psikologis Bagi Narapidana Wanita yang Melakukan Tindak Pidana Pembunuhan dan Upaya Penanggulangannya. Malang: Universitas Brawijaya
Potter, Patricia; Perry, Anne Griffin, 2005. Buku Ajar: Fundamental Keperawatan, Konsep, proses dan praktik. Jakarta: Penerbit EGCGail W. Stuart, 2006. Buku Saku Keperawatan Jiwa. Jakarta: EGC

Sarafino. (1998). United State of America: John Wiley \& Sons

United Nations Office on Drugs and Crime. (2008). Perempuan dan HIV dala Lingkungan Lapas. Retrieved from United Nations Office on Drugs and Crime:https://www.unodc.org/do cuments/hivaids/UNODC_UNAIDS_2008_P erempuan_dan_HIV_dalam_Lin gkungan_Lapas_-_BI.pdf

Schultz, D. 2010. Psikologi Pertumbuhan : Model-model Kepribadian Sehat. Yogyakarta : Kanisius.

Sugiarti, L. (2008). Gambaran Self acceptance pada Wanita Involuntary Childless Skripsi.Jurusan Psikologi Fakultas Fsikologi Universitas Indonesi.

School. Asian Journal OfEducational Research, 3 (2) 8-23.

Wahyuni, E. (2015). Hubungan SelfEfficacy dan Keterampilan Komunikasi dengan Kecemasan Berbicara di Depan Umum. Jurnal Komunikasi Islam, 5(1), hal. 54-82. 